\title{
Impact of IL12B Gene rs 3212227 Polymorphism on Fibrosis, Liver Inflammation, and Response to Treatment in Genotype 4 Egyptian Hepatitis C Patients
}

\author{
Samar Samir Youssef, ${ }^{1}$ Asmaa Mostafa, ${ }^{1}$ Amr Saad, ${ }^{2}$ Moataza Hassan Omran, ${ }^{1}$ Taher El \\ Zanaty, ${ }^{3}$ and Sameh Mohamed Seif ${ }^{4}$ \\ ${ }^{1}$ Microbial Biotechnology Department, National Research Center, El Behooth Street, Dokki, Giza, Egypt \\ ${ }^{2}$ Biochemistry Department, Faculty of Science, Cairo University, Giza, Egypt \\ ${ }^{3}$ Department of Internal Medicine, Faculty of Medicine, Cairo University, Giza, Egypt \\ ${ }^{4}$ National Hepatology and Tropical Medicine Research Institute, Cairo, Egypt
}

Correspondence should be addressed to Samar Samir Youssef; youssefsamar1969@yahoo.com

Received 30 June 2013; Revised 20 August 2013; Accepted 23 August 2013

Academic Editor: Luisella Bocchio-Chiavetto

Copyright (C 2013 Samar Samir Youssef et al. This is an open access article distributed under the Creative Commons Attribution License, which permits unrestricted use, distribution, and reproduction in any medium, provided the original work is properly cited.

Introduction. Hepatitis $\mathrm{C}$ virus (HCV) infection affects almost 3\% of the world's population with the highest prevalence in Egypt (15\%). The standard therapy; pegylated interferon (PEG-IFN) and ribavirin, is effective in only $60 \%$ of Egyptian patients; moreover it is costly, prolonged, and has severe side effects, so prediction of response is essential to reduce burden of unfavorable treatment. Several viral and host factors have been proved to affect response to the treatment PEG-IFN and ribavirin; the strongest of them is polymorphisms near IL28B; nonetheless, nonresponse in patients with favorable IL28B is still unexplained, which implies the importance of studying other immunological factors that may correlate with response. Interleukin 12 (IL-12) is one of the most important proinflammatory cytokine presented with the initiation of immune response, determining Th1 and Th2 differentiation. A functional single nucleotide polymorphism (A/C) at the $3^{\prime}$ untranslated region $\left(3^{\prime} \mathrm{UTR}\right)$ at position 1188 (NCBI SNP database no 3212227) was reported to be associated with responding more efficiently to antiviral combination therapy in HCV genotype 1 infected patients. The present study aims to evaluate association between this polymorphism with fibrosis stages, necroinflammation activity, response to the combined therapy, and gender in Egyptian HCV genotype 4. Material and Methods. A total of 133 Egyptian chronic HCV (CHCV) patients were treated with IFN/RBV and were followed up. IL12B 1188 A/C genotyping was performed using polymerase chain reaction-restriction fragment length polymorphism (PRC-RFLP) analysis. Results. A nonsignificant trend for higher sustained virological response (SVR) was observed in patients homozygote for IL12B 1188 A/C SNP CC genotype (69\% SVR versus 30.8\% NR) only but not in AC and AA genotypes. No association was detected between IL12B $1188 \mathrm{~A} / \mathrm{C}$ polymorphism and less severe fibrosis or less liver activity. By stratification of response according to gender genotype, a significant difference in response between males and females was seen among AA genotype carriers only due to high number of non responder females. Conclusion. IL12B CC genotype appears to have some influence on SVR achievement but not on severe fibrosis and severe necroinflamation activity. Females carrying A/A genotype of IL12B 1188 A/C SNP achieve less SVR than those carrying AC and CC genotypes.

\section{Introduction}

Hepatitis C “The Silent Killer" is a liver disease which means inflammation of the liver caused by the hepatitis $\mathrm{C}$ virus $(\mathrm{HCV})$. It is suspected that there are, at present, more than 200 million $(\sim 3 \%)$ around the world [1] and not less than $15 \%$ of the Egyptian population [2] infected with $\mathrm{HCV}$. Individuals with chronic HCV infection usually remain asymptomatic and undiagnosed for decades before chronic hepatitis leads to severe fibrosis and cirrhosis, hepatic failure, or hepatocellular carcinoma, and it is now recognized as a leading indication for liver transplantation which makes it 
one of the greatest public health threats faced in this century, and perhaps one of the greatest threats to be faced in the next century $[3,4]$.

The current recommended and approved treatment for chronic HCV infection is the combination therapy of pegylated alpha interferon (PEG-IFN) and the oral antiviral drug ribavirin [5]. Response rate to such therapy does not exceed $40 \%$ of the patients infected with genotype $4 \mathrm{a}$, the most prevalent subtype in Egypt [6]. This therapy is costly, prolonged, and associated with significant adverse effects, so prediction of response is essential to reduce the burden of unfavorable treatment.

Cytokines play an important role in differentiation, maturation, and functional activation of immune cells [7]. Interleukin 12 (IL-12) is one of the most important proinflammatory cytokine produced mainly by antigen presenting cells as a result of IFN- $\gamma$ stimulation [8] and presented with the initiation of immune response, so IL12 can be considered as one of the most clearly defined factors determining Th1 and Th2 differentiation $[9,10]$. Therefore, IL-12 might play an important role in the pathogenesis of HCV infection and response to the antiviral therapy by affecting the Th1/Th2 balance.

The gene encoding IL-12 p40 (IL12B) is polymorphic and has a functional single nucleotide polymorphism (A/C) of the $3^{\prime}$ untranslated region ( $\left.3^{\prime} \mathrm{UTR}\right)$ at position 1188 (NCBI SNP database no. 3212227) [11]. Seegers et al. reported that the variant $\mathrm{C}$ allele of the $1188 \mathrm{~A} / \mathrm{C}$ polymorphism has been associated with enhanced IL-12 production [12]; also, previous studies have investigated that IL12B 3 '-UTR 1188-C-allele carriers appear to be associated with both spontaneous viral clearance [13] and responding more efficiently to antiviral combination therapy in HCV genotype 1 infected patients only $[11,14,15]$. Such studies are still lacking in Egypt where the impact of IL-12 A/C polymorphism on response to the antiviral therapy and disease progression is not studied. So in this study, IL12B $3^{\prime}$-UTR 1188-A/C SNP will be studied in Egyptian HCV genotype 4 infected patients to determine the precise relationship between this polymorphism and fibrosis, liver inflammation, and response to the combined therapy, in addition to its relation to the patient gender.

\section{Materials and Methods}

2.1. Study Population. This study included 133 Egyptian patients infected with genotype $4 \mathrm{HCV}$. All patients were recruited from the National Hepatology and Tropical Medicine Research Institute (NHTMRI), Cairo, Egypt, selected according to the following criteria: (i) older than 18 years, (ii) completion of the full course of anti-HCV therapy with PEG-IFN plus RBV, (iii) lack of coinfection with HBV, HIV, EBV, and CMV, (iv) no history of alcohol consumption, (v) no bilharzias or diabetes mellitus, and (vi) no suffering from other autoimmune or hematological diseases. Pretreatment liver biopsy was performed to assess fibrosis and liver inflammation (according to the Metavir Score). Sticking to follow-up visits was scheduled at 4, $12,24,36,48$, and 24 weeks after the planned treatment discontinuation date. At each visit, clinical, biochemical, and hematological assessments were carried out and patients received the combined therapy of PEG-IFN, and oral RBV and therapy were discontinued in case of nonresponders. This study was approved by the local research ethics committee, and a written informed consent was obtained from all the participants in this study.

2.2. Detection of HCV Antibodies. The presence or absence of $\mathrm{HCV}$ antibodies was determined by third generation ELISA (DiaSorin, Torino, Italy).

2.3. Blood Sample and DNA Isolation. A Blood sample of $2 \mathrm{~mL}$ was collected from each individual in sterile anticoagulant tubes. Genomic DNA was extracted using salting out technique [16] and cryopreserved at $-80^{\circ} \mathrm{C}$ for genetic determinations.

2.4. Genotyping of $I L-12 B$ rs 3212227 Polymorphism. One hundred thirty-three patients were genotyped for rs 3212227 SNP using polymerase chain reaction based restriction fragment length polymorphism (PCR-RFLP) analysis assay. Primer pair amplified the SNP region used as described by [14], for forward primer $\left[5^{\prime}\right.$-TTC TAT CTG ATT TGC TTT A-3 $3^{\prime}$ and for reverse primer $\left[5^{\prime}\right.$-CCT ACA TAC CTT ACA AAG T-3']. PCR amplification was carried out in a total volume of $50 \mu \mathrm{L}$ containing $1 \mathrm{x}$ Go Taq Flexi buffer, $1.5 \mathrm{mM} \mathrm{MgCl}_{2}, 0.2 \mathrm{mM}$ of each dNTP, $1 \mathrm{pmol}$ of each primer, 1.25 U Go Taq Flexi DNA Polymerase (Promega), and $20 \mathrm{ng}$ of genomic DNA. PCR cycles involved initial denaturation step at $95^{\circ} \mathrm{C}$ for $8 \mathrm{~min}$ followed by 35 cycles with the following cycle profile: denaturation at $95^{\circ} \mathrm{C}$ for $30 \mathrm{sec}$, annealing temperature $43^{\circ} \mathrm{C}$ for $30 \mathrm{sec}$, extension at $72^{\circ} \mathrm{C}$ for $1 \mathrm{~min}$, and a final extension step at $72^{\circ} \mathrm{C}$ for $10 \mathrm{~min}$. PCR amplicons [233 base pairs (bp)] were digested by $0.5 \mu \mathrm{L}$ (10 U) of Taq1 restriction endonuclease (Promega, Southampton, UK) at $65^{\circ} \mathrm{C}$ for $120 \mathrm{~min}$. Taq -1 recognition site is represented by the presence of $\mathrm{C}$ allele which produces two fragments at 68 and $165 \mathrm{bp}$ while the presence of $\mathrm{A}$ allele is represented by the remain uncut fragment at $233 \mathrm{bp}$. The fragments were separated by $2 \%$ agarose gel electrophoresis then visualized under UV light.

2.5. DNA Sequence Analysis. DNA sequence analysis was performed to three different genotype samples to confirm the integrity of the area surrounding the restriction site. DNA sequence analysis was made to the PCR product using forward primer. The sequenced samples were analyzed in GATC Company using ABI 3730xl automated DNA sequencer. The nucleotide sequence of those amplicons was determined by combining the traditional Sanger dideoxynucleotide chain termination method with the new 454 technology.

2.6. Statistical Analysis. Statistical analysis was performed with the aid of the SPSS 16 software. Data of different variables were expressed as means $\pm \mathrm{SD}$. $T$-test was used to compare means for continuous variables. Also $t$-test was used to compare means for continuous variables in SVR and NR 
TABLE 1: Demographic data and clinical investigations of $133 \mathrm{HCV}$ infected patients.

\begin{tabular}{lc}
\hline Variables & 133 chronic HCV patients \\
\hline Age (years) & $42.5 \pm 9.7$ \\
BMI $\left(\mathrm{Kg} / \mathrm{m}^{2}\right)$ & $27.1 \pm 4.0$ \\
Hemoglobin $(\mathrm{g} / \mathrm{dL})$ & $13.9 \pm 1.6$ \\
Platelet count $\left(10^{3} / \mu \mathrm{L}\right)$ & $216 \pm 67.2$ \\
Baseline ALT $(\mathrm{IU} / \mathrm{L})$ & $68.3 \pm 42.9$ \\
Baseline AST $(\mathrm{IU} / \mathrm{L})$ & $55.6 \pm 37.4$ \\
Total bilirubin $(\mathrm{mg} / \mathrm{dL})$ & $0.62 \pm 0.39$ \\
Total leukocytic count $\left(10^{3} / \mu \mathrm{L}\right)$ & $6.08 \pm 2.08$ \\
\hline Gender & \\
Male & $91(68.4 \%)$ \\
Female & $42(31.6 \%)$ \\
\hline AFP $($ cut off $)$ & $83(62.4 \%)$ \\
$\quad \leq 4.5(\mathrm{ng} / \mathrm{mL})$ & $50(37.6 \%)$ \\
$>4.5(\mathrm{ng} / \mathrm{mL})$ & \\
\hline HCV viral load & $80(60.1 \%)$ \\
$<600,000 \mathrm{IU} / \mathrm{mL}$ & $53(39.9 \%)$ \\
$\geq 600,000 \mathrm{IU} / \mathrm{mL}$ & $2 / 59 / 29 / 36 / 7$ \\
\hline Liver histology $(\mathrm{METAVIR})$ & $7 / 81 / 33 / 12$ \\
F $(n: 0 / 1 / 2 / 3 / 4)$ & \\
A $(n: 0 / 1 / 2 / 3)$ &
\end{tabular}

BMI: body mass index; ALT: alanine aminotransferase; AST: aspartate amino transferase; AFP: alpha-fetoprotein; F: liver fibrosis stage; A: liver activity grade.

patients. Comparison between distributions of categorical variables was performed using Chi-square $\left(\chi^{2}\right)$ test. In addition, variables were described as odds ratio (OR) with $95 \%$ confidence interval (95\% CI) where appropriate. The data were considered significant if $P$ values were $<0.05$ and highly significant if $P<0.01$.

\section{Results}

3.1. Demographic Data and Clinical Investigations of the Study Population. The demographic, biochemical, virological, and histopathological (fibrosis stage and liver inflammation degree) data of 133 chronic HCV infected patients included in the current study were outlined as shown in Table 1.

3.2. Genotype and Allele Frequencies of IL12B SNP in Chronic $\mathrm{HCV}$ Patients. Among our studied population of $\mathrm{HCV}$ infected patients, the frequency of IL12B genotypes was 51\%, $39 \%$, and $10 \%$ for $\mathrm{AA}, \mathrm{AC}$, and CC genotypes, respectively. Also, allele frequency was $70.7 \%$ for A allele and $29.3 \%$ for $\mathrm{C}$ allele. Genotype and allele frequencies of IL12B gene were outlined in Table 2.

3.3. DNA Sequence Analysis for Three Different Genotype Patients. Successful sequencing of CC genotype was proved by detection of a single peak corresponding to $\mathrm{C}$ nucleotide as shown in Figure 1. Similarly, successful sequencing of
TABLE 2: Genotype and allele frequency of IL12B gene in chronic HCV patients.

\begin{tabular}{|c|c|c|c|}
\hline $\begin{array}{l}\text { IL12B genotype and } \\
\text { allele frequency }\end{array}$ & & \multicolumn{2}{|c|}{$\begin{array}{c}\text { HCV infected } \\
\text { patients }[N(\%)]\end{array}$} \\
\hline \multicolumn{4}{|l|}{ Genotype frequency } \\
\hline $\mathrm{AA}$ & & \multicolumn{2}{|c|}{$68(51 \%)$} \\
\hline $\mathrm{AC}$ & & \multicolumn{2}{|c|}{$52(39 \%)$} \\
\hline $\mathrm{CC}$ & & \multicolumn{2}{|c|}{$13(10 \%)$} \\
\hline \multicolumn{4}{|l|}{ Allele frequency } \\
\hline A & \multicolumn{3}{|c|}{$188(70.7 \%)$} \\
\hline $\mathrm{C}$ & \multicolumn{3}{|c|}{$78(29.3 \%)$} \\
\hline \multicolumn{4}{|l|}{$N$ : number. } \\
\hline \multicolumn{4}{|c|}{$\begin{array}{l}\text { TABLE 3: Genotype and allele frequencies of IL12B } 1188 \text { A/C SNP } \\
\text { according to response to the therapy. }\end{array}$} \\
\hline & $\begin{array}{c}\text { SVR } \\
(N=74)\end{array}$ & $\begin{array}{c}\text { NR } \\
(N=59)\end{array}$ & $P$ value \\
\hline \multicolumn{4}{|l|}{ Genotype frequency } \\
\hline $\mathrm{AA}$ & $37(50 \%)$ & $31(52.5 \%)$ & \multirow{3}{*}{0.582} \\
\hline $\mathrm{AC}$ & $28(37.8 \%)$ & $24(40.7 \%)$ & \\
\hline $\mathrm{CC}$ & $9(12.2 \%)$ & $4(6.8 \%)$ & \\
\hline \multicolumn{4}{|l|}{ Allele frequency } \\
\hline A & $102(68.9 \%)$ & $86(72.9 \%)$ & \multirow{2}{*}{0.481} \\
\hline $\mathrm{C}$ & $46(31.1 \%)$ & $32(27.1 \%)$ & \\
\hline
\end{tabular}

AA genotype gives only a single peak corresponding to A nucleotide as shown in Figure 2. While AC genotype sequence was confirmed by the presence of two overlapping peaks as expected (Figure 3).

3.4. Genotype and Allele Frequencies of IL12B 1188 A/C SNP according to Response to the Combined Therapy. Genotype and allele frequencies of IL12B 1188 A/C SNP showed a differential distribution within SVR and NR as shown in Table 3. This difference in genotype distribution between SVR and NR patients did not reach statistically significant association with response to therapy. The distribution, of SVR and NR within individuals carrying the AA genotype was $54.4 \%$ and $45.6 \%$, the AC genotype was $53.8 \%$ and $46.2 \%$, and the CC genotype was $69.2 \%$ and $30.8 \%$, so it is quite noted that the ratio of CC carrying patients in SVR is about to be twice that of NR reflecting an impact of this genotype on response to treatment. This effect of CC genotype replicated only when the recessive model was applied where $69.2 \%$ of patients with CC genotype were SVR versus $54.2 \%$ in patients with AA + AC genotypes as shown in Table 4.

Regarding the allele frequency, a differential distribution was observed in the allele frequency of IL12B 1188 A/C SNP in SVR versus NR. Notably, the percent of patients harboring the C allele who achieved SVR (46 out of 78: 59\%) is more than those from A allele carriers (102 of 188: 54.3\%).

3.5. The Correlation between IL12B 1188 A/C SNP and Stages of Liver Fibrosis. A clear differential distribution was observed 
TABLE 4: Recessive model of inheritance of IL12B 1188 A/C polymorphism in SVR versus NR HCV patients.

\begin{tabular}{|c|c|c|c|c|c|c|}
\hline \multirow{2}{*}{ IL12B 1188 A/C } & \multirow{2}{*}{$\operatorname{SVR}(N=74)$} & \multirow{2}{*}{$\mathrm{NR}(N=59)$} & \multirow{2}{*}{ Odds ratio $(\mathrm{OR})$} & \multicolumn{2}{|c|}{ 95\% Confidence interval $(95 \% \mathrm{CI})$} & \multirow{2}{*}{$P$ value } \\
\hline & & & & Lower & Upper & \\
\hline \multicolumn{7}{|l|}{ Recessive model } \\
\hline $\mathrm{AA}+\mathrm{AC}$ & $65(87.8 \%)$ & $55(93.2 \%)$ & 6.522 & 0.556 & 1.904 & 0.299 \\
\hline $\mathrm{CC}$ & $9(12.2 \%)$ & $4(6.8 \%)$ & 0.022 & 0.350 & 1.304 & 0.299 \\
\hline
\end{tabular}

TABLE 5: The correlation between IL12B 1188 A/C SNP and degree of liver fibrosis.

\begin{tabular}{lccc}
\hline & $\begin{array}{c}\text { F0-F2 } \\
(N=90)\end{array}$ & $\begin{array}{c}\text { F3-F4 } \\
(N=43)\end{array}$ & $P$ value \\
\hline Genotype frequency & & & \\
AA & $43(47.8 \%)$ & $25(58.1 \%)$ & \\
AC & $38(42.2 \%)$ & $14(32.6 \%)$ & 0.517 \\
CC & $9(10 \%)$ & $4(9.3 \%)$ & \\
\hline Allele frequency & & & \\
A & $124(68.9 \%)$ & $64(74.4 \%)$ & 0.354 \\
C & $56(31.1 \%)$ & $22(25.6 \%)$ & \\
\hline
\end{tabular}

TABLE 6: The correlation between IL12B 1188 A/C SNP and grade of liver necroinflamation activity.

\begin{tabular}{lccc}
\hline & $\begin{array}{c}\text { A0-A1 } \\
(N=88)\end{array}$ & $\begin{array}{c}\text { A2-A3 } \\
(N=45)\end{array}$ & $P$ value \\
\hline Genotype frequency & & & \\
AA & $40(45.5 \%)$ & $28(62.2 \%)$ & \\
AC & $39(44.3 \%)$ & $13(28.9 \%)$ & 0.173 \\
CC & $9(10.2 \%)$ & $4(8.9 \%)$ & \\
\hline Allele frequency & & & \\
A & $119(67.6 \%)$ & $69(76.7 \%)$ & 0.125 \\
C & $57(32.4 \%)$ & $21(23.3 \%)$ & \\
\hline
\end{tabular}

in IL12B genotypes according to stages of liver fibrosis (mild/moderate (F0-F2) versus severe (F3-F4) liver fibrosis) as shown in Table 5 . This difference in genotype distribution between F0-F2 and F3-F4 patients did not reach significant association with fibrosis progression $(P=0.517)$. Also, IL12B alleles showed a nonsignificant differential distribution in different stages of liver fibrosis (mild/moderate (F0-F2) versus severe (F3-F4) liver fibrosis) $(P=0.354)$.

\subsection{The Correlation between IL12B 1188 A/C SNP and Grade} of Liver Necroinflammation Activity. Differential distribution was seen in both IL12B genotype and allele frequencies according to mild (A0-A1) and sever (A2-A3) liver necroinflammation activity as shown in Table 6 . This difference in genotype distribution did not reach a significant association with liver necroinflammation activity $(P=0.173)$. Also, distribution of IL12B alleles in mild (A0-A1) versus sever (A2A3) liver activity did not reach the significant level $(P=$ $0.125)$.

3.7. Influence of IL12B 1188 A/C SNP Stratified according to Gender Parameter on Response to Antiviral Therapy. Results

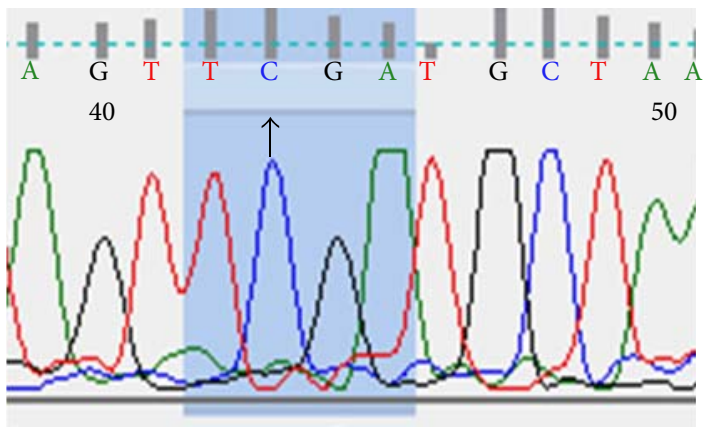

FIGURE 1: DNA sequencing of CC genotype patient.

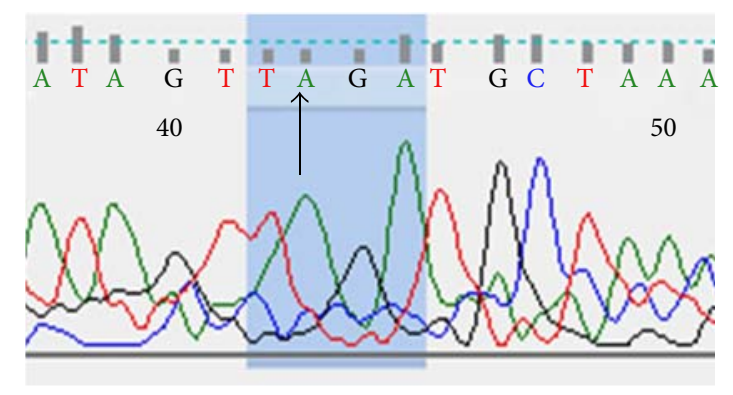

FIGURE 2: DNA sequencing of AA genotype patient.

of the effect of IL12B genotypes and alleles on response to the combined therapy stratified according to gender are outlined as shown in Table 7. Our results showed that in both males and females, those carrying the CC genotype were more likely to achieve SVR than those carrying $\mathrm{AC}$ and $\mathrm{AA}$; as among CC male carriers $77.8 \%$ (7 out of 9 CC males) were SVR compared to $63 \%$ and $61.1 \%$ of $\mathrm{AA}$ and $\mathrm{AC}$ male carriers, respectively. In females, $50 \%$ (2 out of $4 \mathrm{CC}$ females) were SVR versus $36.4 \%$ and $37.5 \%$ of AC and AA female carriers. Results of studying each genotype separately showed that a statistically significant difference between response in males and females was obtained for AA genotype carriers only $(P=$ $0.039)$ and not for AC $(P=0.115)$ or CC $(P=0.317)$ patients which may be a consequence of having the highest percentage of nonresponder females (63.6\%) in the AA genotype, concomitant with a high percentage of response in males (63\%), which may reflect the extent of bad prognostic role in AA genotype carrying females than males. Also, allele frequency of IL12B 1188 A/C SNP in males and females within SVR and NR patients showed no significant difference. Nonetheless, the percent of male patients achieving SVR was higher in those carrying the $\mathrm{C}$ allele compared to those carrying the A allele (66.7\% versus $62.5 \%$, resp.), and similarly 


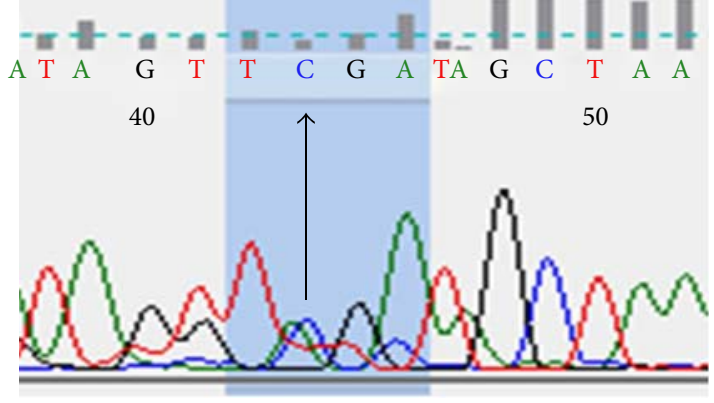

FIGURE 3: DNA sequencing of AC genotype patient.

the percent of females who achieved SVR was higher in females carrying the $\mathrm{C}$ allele than those with A allele (41.7\% versus $36.7 \%$, resp.).

\section{Discussion}

Cytokines play an important role in differentiation, maturation and functional activation of immune cells [7]. Interleukin 12 (IL-12) is one of the most important proinflammatory cytokine produced mainly by antigen presenting cells as a result of IFN- $\gamma$ stimulation [8]. IL-12 is a key cytokine presented with the initiation of immune response, which is one of the most clearly defined factors determining Thl and Th2 differentiation $[9,10]$. Therefore, IL-12 might play an important role in the pathogenesis of $\mathrm{HCV}$ infection and response to the antiviral therapy by affecting the Th1/Th2 balance. The gene encoding IL-12 p40 (IL12B) is polymorphic, located on 5q31-33 [17], and has a functional single nucleotide polymorphism $(\mathrm{A} / \mathrm{C})$ at the $3^{\prime}$ untranslated region $\left(3^{\prime} \mathrm{UTR}\right)$ at position 1188 (NCBI SNP database no 3212227) [11]. Seegers et al. reported that the variant C allele of the 1188 A/C polymorphism has been associated with enhanced IL12 production [12]. On the other hand, previous studies have investigated the association of IL12B $3^{\prime}$-UTR 1188-Callele carriers with both spontaneous viral clearance [13] and treatment induced clearance in HCV genotype 1 infected patients only $[11,14,15]$, but till now this was not studied in G4. It was previously proved that all SNPs genotyped in IL12B showed significant variation in allele frequency by race [18]. The present study is the first to assess the role of IL12B $3^{\prime}$ UTR $1188-\mathrm{A} / \mathrm{C}$ SNP in response to the combined therapy, fibrosis stages, necroinflammation activity and gender in Egyptian HCV genotype 4 infected patients treated with PEG-IFN and ribavirin combined therapy.

IL12B rs 3212227 SNP was genotyped in total of $133 \mathrm{HCV}$ infected patients; the genotype distribution in SVR patients was $50 \%, 37.8 \%$, and $12.2 \%$ for $\mathrm{AA}, \mathrm{AC}$, and CC genotypes, respectively, while in NR patients was $52.5 \%, 40.7 \%$, and $6.8 \%$ for AA, AC, and CC genotypes, respectively. This difference in genotype distribution between SVR and NR patients did not reach statistically significant association with response to therapy $(P=0.582)$, and these results agreed with the Farooqi et al., 2011, results who studied $3^{\prime}$-UTR 1188-A/C SNP on Pakistani patients with 3a genotype HCV infection and
TABLE 7: Influence of IL12B 1188 A/C SNP stratified according to gender parameter on response to antiviral therapy.

\begin{tabular}{lccc}
\hline Genotype $^{\mathrm{a}}$ & $\begin{array}{c}\text { SVR } \\
(N=74)\end{array}$ & NR $(N=59)$ & $P$ value \\
\hline AA $^{\mathrm{b}}$ genotype & & & \\
$\mathrm{M}$ & $29(39.2 \%)$ & $17(28.8 \%)$ & \\
$\mathrm{F}$ & $8(10.8 \%)$ & $14(23.7 \%)$ & \\
AC $^{\mathrm{c}}$ genotype & & & \\
$\mathrm{M}$ & $22(29.7 \%)$ & $14(23.7 \%)$ & \\
$\mathrm{F}$ & $6(8.1 \%)$ & $10(17 \%)$ & \\
CC ${ }^{\mathrm{d}}$ genotype & & & \\
$\mathrm{M}$ & $7(9.5 \%)$ & $2(3.4 \%)$ & \\
$\mathrm{F}$ & $2(2.7 \%)$ & $2(3.4 \%)$ & \\
\hline A allele & & & \\
M & $80(54.1 \%)$ & $48(40.7 \%)$ & \\
F & $22(14.9 \%)$ & $38(32.2 \%)$ & \\
C allele & & & \\
M & $36(24.3 \%)$ & $18(15.2 \%)$ & \\
F & $10(6.7 \%)$ & $14(11.9 \%)$ & \\
\hline
\end{tabular}

M: male; $\mathrm{F}$ : female; ${ }^{\mathrm{a}}$ cross tab for distribution of males and females in relation to IL12B genotypes $P=0.981 ;{ }^{b}$ cross tab for distribution of AA males and females in relation to response $P=0.039 ;{ }^{c}$ cross tab for distribution of AC males and females in relation to response $P=0.115{ }^{d}{ }^{d}$ cross tab for distribution of CC males and females in relation to response $P=0.317$.

reported that there is no significant association between 1188 A/C SNP and response to the therapy [19]. Nonetheless, we cannot neglect that among patients carrying CC genotype, $69.2 \%$ achieved sustained virological response compared to $30.8 \%$ were NR reflecting the impact of this genotype on response to treatment. This is concordant with Mueller et al., who have shown that $\mathrm{HCV}$ patients with the $\mathrm{C} / \mathrm{C}$ genotype were able to respond more efficiently to the antiviral therapy [15].

Regarding the allele frequency, the difference in distribution of A and C-alleles of IL12B $3^{\prime}$-UTR 1188-A/C SNP between SVR and NR was not significantly associated with response to therapy $(P=0.481)$. Our result showed higher percentage of SVR patients within C versus A allele carriers (59\% versus $54.3 \%$, resp.) which proves that the presence of $\mathrm{C}$ allele tends to achieve sustained response to PEG-IFN and Ribavirin combined therapy. Mueller et al. supported our investigations as they demonstrated that there is a nonsignificant trend associating the IL12B 3 '-UTR 1188-C allele with increased SVR (61.1\% compared to $54.5 \%$ SVR for the A allele, $P=0.075)$ [15].

Regarding the correlation of IL12B 1188 A/C genotypes with fibrosis, no significant association was seen between genotypes and mild fibrosis versus severe fibrosis $(P=0.517)$. This contraindicates the finding of Suneetha et al. who proved that distribution of CC genotype was significantly less in patients with severe fibrosis and that $\mathrm{C} / \mathrm{C}$ genotype may have a protective role in $\mathrm{HCV}$ induced liver fibrosis patients when compared with A/A and A/C genotypes [20]. Also our study is not in agreement with the study of Mueller et al. who reported that a significantly higher rate of advanced liver 
fibrosis (F3-F4) was observed in patients having CC genotype $(P=0.039)[15]$.

Investigation of the correlation between IL12B $1188 \mathrm{~A} / \mathrm{C}$ SNP and degree of liver necroinflammation revealed no significant association, which matches Suneetha et al. who demonstrated that IL12B 1188 A/C SNP has no statistically significant association with liver necroinflammation activity [20] and Mueller et al. who demonstrated that the IL12B $3^{\prime}$ UTR polymorphism had no influence on the grade of hepatic inflammation [15].

From all the above, it can be concluded that a trend is observed relating the CC genotype with more SVR. This may be due to association of IL12B 1188 A/C SNP C allele with increased production of IL 12 which consequently promotes TH1 cell development and secretion of IFN $\gamma$ and TNF $\alpha$, which will exert their noncytopathic antiviral actions.

Susceptibility to response to the antiviral therapy differs by gender as it was reported by Narciso-Schiavon et al. that women and men react differently to the combined therapy [21]; also Sezaki and colleagues demonstrated that SVR rates were poorer in women than men who were aged $\geq 50$ years $(P<0.001)$ who revealed this result to low estrogen levels in older women which could be responsible for their impaired response to PEG-IFN and ribavirin treatment [22]. Our investigations in this study revealed that gender has a highly statistically significant difference in SVR and NR patients $(P=0.006)$. In order to study the role of gender on genetic susceptibility to respond to the antiviral therapy, IL12B $3^{\prime}$ UTR 1188-A/C SNP was stratified according to gender and compared between SVR and NR patients. Our study showed a significant association $(P=0.039)$ between gender and response to the therapy in AA genotype carriers only and not seen in $\mathrm{AC}(P=0.115)$ and $\mathrm{CC}(P=0.317)$ genotypes, which may be attributed to the highest percentage of nonresponder females in AA carriers. As none of the existing studies addressed the correlation between gender response and IL12B $3^{\prime}$-UTR 1188-A/C polymorphism, no further interpretation can be made in this regards.

In conclusion, the results of the present study reveals that IL12B $3^{\prime}$-UTR 1188-C/C appears to have some influence on the response to the combined therapy in the Egyptian patients infected with genotype $4 \mathrm{HCV}$ as increased SVR rates were observed in those who carried at least one IL12B C-allele. This study showed also that IL12B 3'-UTR 1188-C/C has no significant influence on either stage of liver fibrosis or grade of necroinflammation activity. Finally, this study is the first one that assesses the significant correlation between stratification of IL12B $3^{\prime}$-UTR 1188-A/C by gender and response to the antiviral therapy as AA genotype indicates females who are at high risk of nonresponse to the therapy. So IL12B 3'- UTR $1188-\mathrm{A} / \mathrm{C}$ can be considered as a prognostic marker for drug responses in Egyptian HCV patients.

\section{References}

[1] S. Rehman, U. A. Ashfaq, S. Riaz, T. Javed, and S. Riazuddin, "Antiviral activity of Acacia nilotica against Hepatitis C Virus in liver infected cells," Virology Journal, vol. 8, article 220, 2011.
[2] M. J. Alter, "Epidemiology of hepatitis C virus infection," World Journal of Gastroenterology, vol. 13, no. 17, pp. 2436-2441, 2007.

[3] P. Ferenci, S. Ferenci, C. Datz, I. Rezman, W. Oberaigner, and R. Strauss, "Morbidity and mortality in paid Austrian plasma donors infected with hepatitis $C$ at plasma donation in the 1970s," Journal of Hepatology, vol. 47, no. 1, pp. 31-36, 2007.

[4] J.-C. Duclos-Vallee and M. Sebagh, "Recurrence of autoimmune disease, primary sclerosing cholangitis, primary biliary cirrhosis, and autoimmune hepatitis after liver transplantation," Liver Transplantation, vol. 15, supplement 2, pp. S25-S34, 2009.

[5] G. Borroni, M. Andreoletti, M. A. Casiraghi et al., "Effectiveness of pegylated interferon/ribavirin combination in "real world" patients with chronic hepatitis C virus infection," Alimentary Pharmacology and Therapeutics, vol. 27, no. 9, pp. 790-797, 2008.

[6] M. P. Manns, J. G. McHutchison, S. C. Gordon et al., "Peginterferon alfa- $2 \mathrm{~b}$ plus ribavirin compared with interferonalfa$2 \mathrm{~b}$ plus ribavirin for initial treatment of chronic hepatitis C: a randomised trial," The Lancet, vol. 358, no. 9286, pp. 958-965, 2001.

[7] L. Wan, Y.-J. Kung, Y.-J. Lin et al., "Th1 and Th2 cytokines are elevated in HCV-infected SVR(-) patients treated with interferon- $\alpha$," Biochemical and Biophysical Research Communications, vol. 379, no. 4, pp. 855-860, 2009.

[8] M. Del Vecchio, E. Bajetta, S. Canova et al., "Interleukin-12: biological properties and clinical application," Clinical Cancer Research, vol. 13, no. 16, pp. 4677-4685, 2007.

[9] G. Trinchieri, S. Pflanz, and R. A. Kastelein, “The IL-12 family of heterodimeric cytokines: new players in the regulation of $\mathrm{T}$ cell responses," Immunity, vol. 19, no. 5, pp. 641-644, 2003.

[10] W. T. Watford, M. Moriguchi, A. Morinobu, and J. J. O'Shea, "The biology of IL-12: coordinating innate and adaptive immune responses," Cytokine and Growth Factor Reviews, vol. 14, no. 5, pp. 361-368, 2003.

[11] D. Huang, M. R. Cancilla, and G. Morahan, "Complete primary structure, chromosomal localisation, and definition of polymorphisms of the gene encoding the human interleukin-12 p40 subunit," Genes and Immunity, vol. 1, no. 8, pp. 515-520, 2000.

[12] D. Seegers, A. Zwiers, W. Strober, A. S. Peña, and G. Bouma, "A TaqI polymorphism in the 3' UTR of the IL-12 p40 gene correlates with increased IL-12 secretion," Genes and Immunity, vol. 3, no. 7, pp. 419-423, 2002.

[13] A. Houldsworth, M. Metzner, S. Rossol et al., "Polymorphisms in the IL-12B gene and outcome of HCV infection," Journal of Interferon and Cytokine Research, vol. 25, no. 5, pp. 271-276, 2005.

[14] M. A. Hall, E. McGlinn, G. Coakley et al., "Genetic polymorphism of IL-12 p40 gene in immune-mediated disease," Genes and Immunity, vol. 1, no. 3, pp. 219-224, 2000.

[15] T. Mueller, A. Mas-Marques, C. Sarrazin et al., "Influence of interleukin 12B (IL12B) polymorphisms on spontaneous and treatment-induced recovery from hepatitis $\mathrm{C}$ virus infection," Journal of Hepatology, vol. 41, no. 4, pp. 652-658, 2004.

[16] S. A. Miller, D. D. Dykes, and H. F. Polesky, "A simple salting out procedure for extracting DNA from human nucleated cells," Nucleic Acids Research, vol. 16, no. 3, p. 1215, 1988.

[17] D. Sieburth, E. W. Jabs, J. A. Warrington et al., "Assignment of genes encoding a unique cytokine (IL12) composed of two unrelated subunits to chromosomes 3 and 5," Genomics, vol. 14, no. 1, pp. 59-62, 1992.

[18] A. L. Van Dyke, M. L. Cote, A. S. Wenzlaff, S. Land, and A. G. Schwartz, "Cytokine SNPs: comparison of allele frequencies by 
race and implications for future studies," Cytokine, vol. 46, no. 2, pp. 236-244, 2009.

[19] Z. Farooqi, M. Afzal, S. Tahir, N. Zaidi, and I. Qadri, "Interleukin-12 P40 (IL-12 B) Taq-1 Polymorphism association in pharmacogenomics of HCV genotype 3 a infection from Pakistani population," in Proceedings of the International Conference on Environmental, Biomedical and Biotechnology, 2011.

[20] P. V. Suneetha, A. Goyal, S. S. Hissar, and S. K. Sarin, "Studies on TAQ1 polymorphism in the $3^{\prime}$ untranslated region of IL-12P40 gene in HCV patients infected predominantly with genotype 3," Journal of Medical Virology, vol. 78, no. 8, pp. 1055-1060, 2006.

[21] J. L. Narciso-Schiavon, L. D. L. Schiavon, R. J. Carvalho-Filho et al., "Gender influence on treatment of chronic hepatitis C genotype 1," Revista da Sociedade Brasileira de Medicina Tropical, vol. 43, no. 3, pp. 217-223, 2010.

[22] H. Sezaki, F. Suzuki, Y. Kawamura et al., "Poor response to pegylated interferon and ribavirin in older women infected with hepatitis C virus of genotype $1 \mathrm{~b}$ in high viral loads," Digestive Diseases and Sciences, vol. 54, no. 6, pp. 1317-1324, 2009. 